\title{
Geologic setting of serpentine deposits on Mars
}

\author{
B. L. Ehlmann, ${ }^{1}$ J. F. Mustard, ${ }^{1}$ and S. L. Murchie ${ }^{2}$ \\ Received 18 January 2010; revised 23 February 2010; accepted 25 February 2010; published 25 March 2010.
}

[1] Serpentine, recently discovered on Mars using Mars Reconnaissance Orbiter data, is uncommon but found in three geologic settings: (1) in mélange terrains at the Claritas Rise and the Nili Fossae, (2) associated with a few southern highlands impact craters, and (3) associated with a regional olivine-rich stratigraphic unit near the Isidis basin. Any presently active serpentinization processes would be occurring beneath the surface and mineral products would not be apparent with surface and orbital data; however, finding serpentine in several Noachian terrains indicates active serpentinization processes in Mars' past. Important implications are the past production of magnetite, which may contribute to chemical remnant magnetization of Mars' crust, and production of $\mathrm{H}_{2}$, which is a suitable energy source for chemosynthetic microbial life. Citation: Ehlmann, B. L., J. F. Mustard, and S. L. Murchie (2010), Geologic setting of serpentine deposits on Mars, Geophys. Res. Lett., 37, L06201, doi:10.1029/2010GL042596.

\section{Introduction}

[2] Serpentines are 1:1 trioctahedral phyllosilicates with the general formula $(\mathrm{Mg}, \mathrm{Fe})_{3} \mathrm{Si}_{2} \mathrm{O}_{5}(\mathrm{OH})_{4}$ and form during hydrothermal alteration of ultramafic rocks at temperatures ranging from slightly above ambient to approximately $400^{\circ} \mathrm{C}$ [e.g., Evans, 2004]. The presence of serpentine serves as a marker for distinctive aqueous chemical conditions: highly reducing, high $\mathrm{pH}$, and low $\mathrm{aSiO}_{2}$. Serpentine's existence on Mars is of significance for considerations of geophysics and habitability. Depending on fluid geochemistry during serpentinization, a commonly accompanying product is magnetite $\left(\mathrm{Fe}_{3} \mathrm{O}_{4}\right)$, which is highly susceptible to magnetism and has been hypothesized to contribute to the generation of Martian magnetic anomalies [Nazarova and Harrison, 2000; Lillis et al., 2008]. Serpentinzation reactions also produce $\mathrm{H}_{2}$, which can serve as an important energy source for chemosynthetic organisms [Schulte et al., 2006] or react abiotically with $\mathrm{CO}_{2}$ to produce methane [Oze and Sharma, 2005].

[3] Data from orbiting visible/near-infrared imaging spectrometers have revealed phyllosilicate minerals in Mars' oldest crust, the Noachian southern highlands. While most phyllosilicates found to date on Mars are $\mathrm{Fe} / \mathrm{Mg}$ smectites or chlorites [Mustard et al., 2008; Poulet et al., 2005], which can form under a variety of conditions, less commonly occurring minerals such as recently identified serpentine

\footnotetext{
${ }^{1}$ Geological Sciences, Brown University, Providence, Rhode Island, USA.

${ }^{2}$ Johns Hopkins University Applied Physics Laboratory, Laurel, Maryland, USA.

Copyright 2010 by the American Geophysical Union. 0094-8276/10/2010GL042596
}

[Ehlmann et al., 2009] provide more specific information on past geochemical conditions. Here we catalogue the geologic settings of serpentine-bearing deposits found so far by the Compact Reconnaissance Imaging Spectrometer for Mars (CRISM). We also discuss the prevalence of serpentine on Mars, likely constraints for its formation and persistence, and implications for geophysical and astrobiological studies.

\section{Identification of Serpentine-Bearing Rocks}

[4] Thousands of targeted, atmospherically corrected CRISM observations (18-40 m/pixel) [Murchie et al., 2009] have been examined in the southern highlands for evidence of alteration minerals, including serpentine. Serpentine is relatively uncommon. To ensure no deposits had been overlooked in prior analyses, 162 observations in areas that show strong signatures of olivine [Poulet et al., 2007; Koeppen and Hamilton, 2008] or evidence for $\mathrm{Fe} / \mathrm{Mg}$ phyllosilicates as indicated by the D2300 parameter [Murchie et al., 2009] were re-examined in this study (for image processing methods, see Ehlmann et al. [2009]).

[5] Serpentine has characteristic absorptions in the 1.0 $2.6 \mu \mathrm{m}$ region that result from bending and stretching of metal(Mg,Fe, $\mathrm{Al})-\mathrm{OH}$ bonds [e.g., Calvin and King, 1997, and references therein] (Figure 1). The Mg-rich polytypes antigorite, lizardite, and chrysotile are indistinguishable at CRISM resolution. Their strongest absorption is an asymmetric, narrow $2.325 \mu \mathrm{m} \mathrm{Mg-OH}$ combination band. Near $1.4 \mu \mathrm{m}$, is a narrow $\mathrm{OH}$ stretch overtone, centered at $1.38 \mu \mathrm{m}$ for $\mathrm{Mg}$ serpentines. A $\mathrm{v}$-shaped band centered at 2.50 $2.52 \mu \mathrm{m}$ and a weaker feature at $2.10-2.12 \mu \mathrm{m}$, whose strength varies markedly with grain size [Bishop et al., 2008], are also characteristic. The presence of all four of these absorption features is necessary to uniquely distinguish magnesian serpentines from other alteration minerals on Mars, such as carbonates, chlorites, Mg-rich smectites, and their mixtures [Ehlmann et al., 2009]. Stoichiometric serpentine would not have molecular water in its structure, but spectra observed with CRISM, as well as many terrestrial serpentine samples, have a $1.9-\mu \mathrm{m}_{2} \mathrm{O}$ absorption caused by either intermixed hydrated phases or an imperfectly crystalline form. Iron-rich serpentines have a different set of absorptions [Calvin and King, 1997]. Chamosite and berthierine have distinctive absorptions that were searched for and not found. Greenalite and cronstedite lack VNIR absorption features that uniquely distinguish them from other alteration products and their mixtures, and it is probably impossible to unambiguously determine their presence or absence on Mars from orbital data. On Figure 2, definitive and probable serpentine detections, all $\mathrm{Mg}$-rich, are delineated. Probable serpentines have the characteristic shape and band positions of serpentine and are distinctive from other 


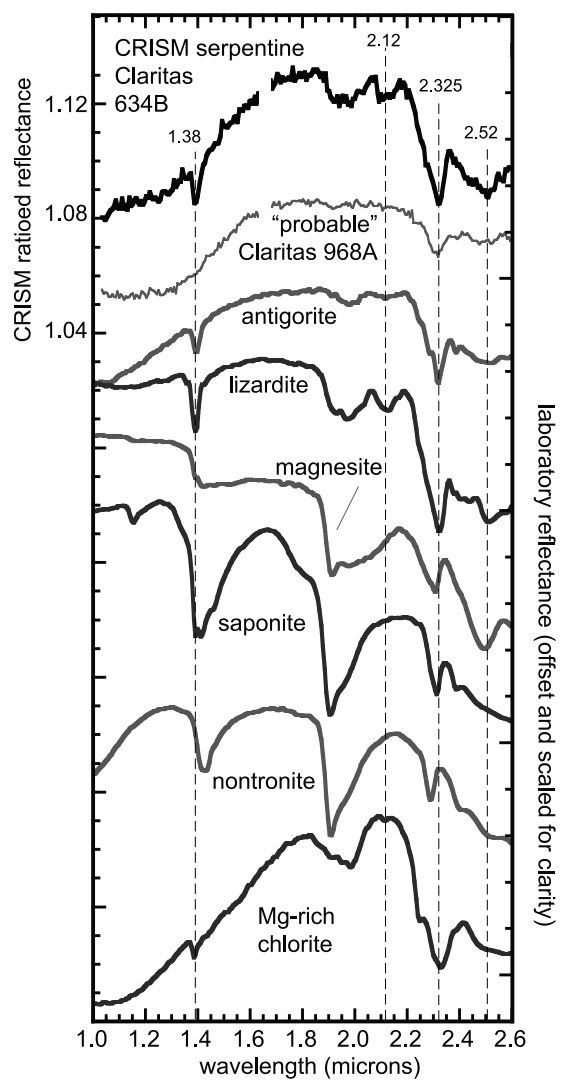

Figure 1. A CRISM spectrum from the Claritas Rise (ratioed to nearby bland material to highlight the features) possesses four distinctive near-infrared absorptions that permit the unique identification of serpentine (laboratory spectra from Clark et al. [2007]). An example spectrum of "probable" serpentine-bearing materials from a nearby scene has only some of the diagnostic features. materials in the scene examined but may be lacking the weaker absorption features (Figure 1).

\section{Geologic Settings}

[6] All serpentine detections to date occur in rocks of three geologic settings: (1) in mélanges with other alteration minerals, (2) in the central peaks, walls, and ejecta of impact craters, and (3) in direct association with olivine-rich rocks.

\subsection{Mélange Terrains}

[7] Fourteen CRISM images were examined from the Claritas Rise, a faulted topographic high, which formed during Noachian, pre-Tharsis uplift and tectonism [Anderson et al., 2001] and hosts a large crustal magnetic anomaly [Acuña et al., 1999]. Fe/Mg smectite and chlorite are the most common alteration minerals observed in nine images; three images show evidence of serpentine. In the largest exposures $\left(26.8^{\circ} \mathrm{S},-101.2^{\circ} \mathrm{E}\right)$, raised knobs host serpentinebearing rocks along with chlorite, kaolinite, and illite or muscovite (Figure 3a). Even at $5 \mathrm{~m} /$ pixel resolution, no stratigraphic relationship or regular zoning of the minerals is observed, although the strongest signatures are found in local topographic highs and debris being shed from these.

[8] West of the Nili Fossae $\left(20.9^{\circ} \mathrm{N}, 73.3^{\circ} \mathrm{E}\right)$, where erosion has exposed rock beneath a dark-toned cap rock, CRISM spectra exhibit absorptions characteristic of serpentine, $\mathrm{Fe} / \mathrm{Mg}$ smectite, kaolinite, low-calcium pyroxene, and olivine, each in discrete areas (Figure 3b). The mineralbearing units represent a mélange of Noachian rocks with varying degrees of alteration. Examination of high-resolution imagery generally reveals no coherent stratigraphy or zoning. A possible exception is in a $\sim 3-\mathrm{km}^{2}$ area in the center of the CRISM image that shows a central area of serpentine ringed by $\mathrm{Fe} / \mathrm{Mg}$ smectite, although no distinct unit boundaries can be discerned. Throughout the scene, olivine is partially altered and exhibits $1.9-$ and $2.32-\mu \mathrm{m}$ absorptions which are characteristic of either serpentine or saponite. This may indicate incipient alteration of olivine, or sub-pixel $(<18 \mathrm{~m}$ in scale) spatial mixing of olivine-bearing materials with altered materials.

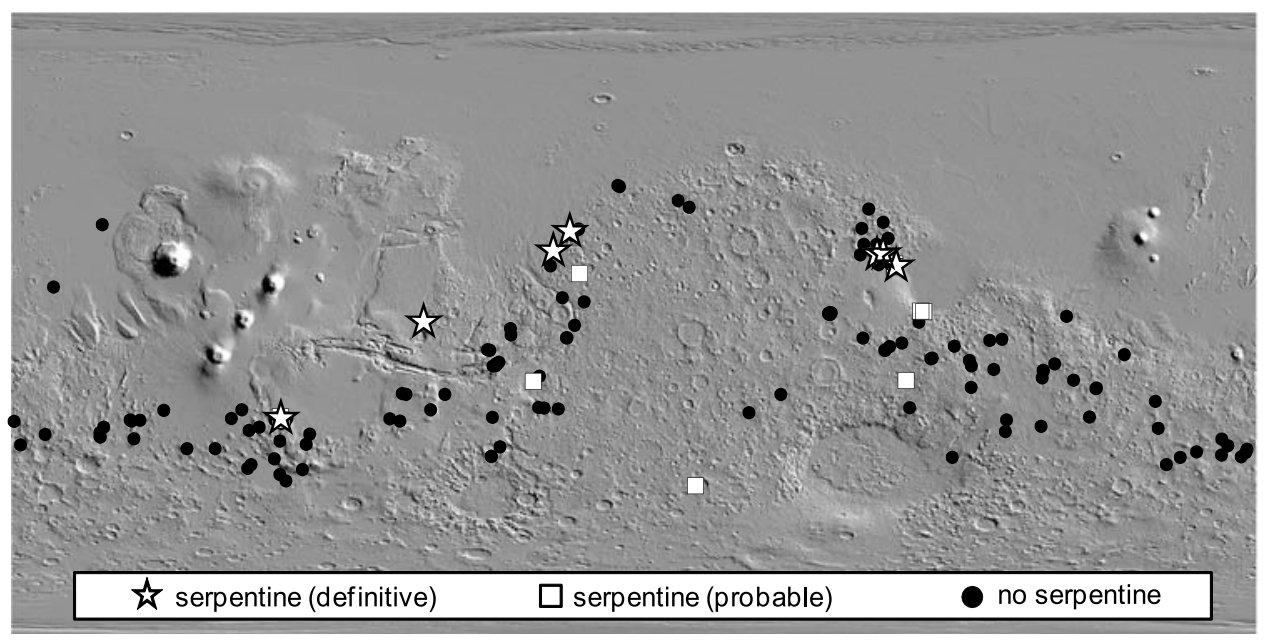

Figure 2. Global hillshade map of Mars from the Mars Orbiter Laser Altimeter (MOLA) indicating locations of serpentine-bearing materials and CRISM images analyzed in this study. 

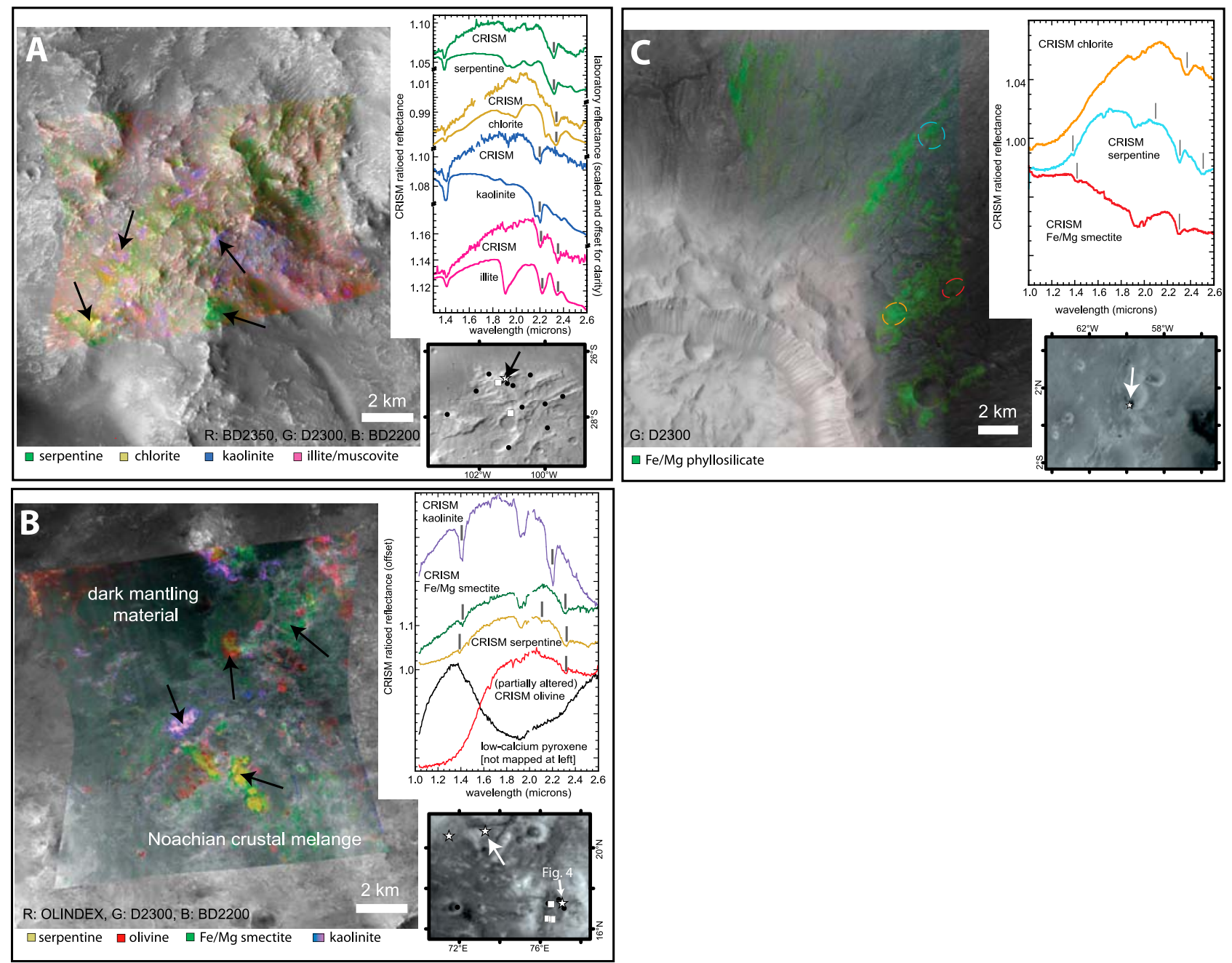

Figure 3. Serpentine in mélange and cratered terrains. CRISM parameter maps were used to colorize CTX images which show the morphology of materials bearing serpentine and other minerals (a) Claritas Rise, CRISM image FRT0000634B on CTX image P08_004108_1522_XI; (b) Nili Fossae, CRISM image FRT0000ABCB on CTX image P19_008347_2019_XN; (c) a small crater within Chia Crater, CRISM image HRL000095C7 on CTX image P15_006849_1815_XN. Colors of spectra correspond to colored areas on the images with those minerals. Spectra locations are indicated by arrows and circles.

\subsection{Southern Highlands Craters}

[9] A small number of craters ( $\sim 5 \%$ of those examined) scattered throughout the southern highlands exhibit spectral signatures consistent with serpentine, e.g., ejecta from a small crater within Chia crater, north of Valles Marineris $\left(1.1^{\circ} \mathrm{N},-59.8^{\circ} \mathrm{E}\right)$ (Figure $\left.3 \mathrm{c}\right)$. These craters are found in Noachian terrains By contrast, two-thirds of the craters in this study have materials bearing chlorite and $\mathrm{Fe} / \mathrm{Mg}$ smectite. Serpentine is found in rocks of the central peaks, walls, and ejecta. Because of the small size of some of the exposures $(<5 \times 5$ CRISM pixels $)$, it is often not possible to uniquely identify serpentine by the presence of characteristic but weak 1.38- and 2.1- $\mu \mathrm{m}$ absorptions and many of these crater serpentine detections are "probable".

\subsection{Noachian Bedrock in Stratigraphic Section}

[10] West of the Isidis basin, Early Hesperian Syrtis Major volcanic flows overlie Noachian bedrock. The Noachian strata consist of an $\mathrm{Fe} / \mathrm{Mg}$ smectite-bearing unit beneath an olivine-rich unit that in places has been partially altered to both carbonate and serpentine [Hamilton and Christensen, 2005; Mustard et al., 2009; Ehlmann et al., 2009]. North of the Noachian-Hesperian contact $\left(17.3^{\circ} \mathrm{N}, 77.2^{\circ} \mathrm{E}\right)$, erosion exposes a $>150-\mathrm{km}^{2}$ outcrop of the olivine-rich unit, which is relatively bright-toned, highly fractured, and variably covered by dunes. The dunes, presumably derived from the bedrock, have spectral signatures of olivine without spectral evidence for alteration products. However, CRISM data indicate the olivine-rich bedrock composition here is heterogeneous, exhibiting partial alteration in most places to magnesium carbonate and in other places to serpentine (Figure 4). At the $5-\mathrm{m} / \mathrm{pixel}$ scale of CTX images, the morphology of the bedrock is similar regardless of alteration mineralogy. Examination of $25 \mathrm{~cm} /$ pixel HiRISE images shows that it is fractured into meter-scale, angular blocks in a quasi-linear pattern with a fracture spacing of $<2 \mathrm{~m}$.

[11] Elsewhere north of, in, and around the Nili Fossae, the olivine-rich bedrock also exhibits signs of partial alter- 

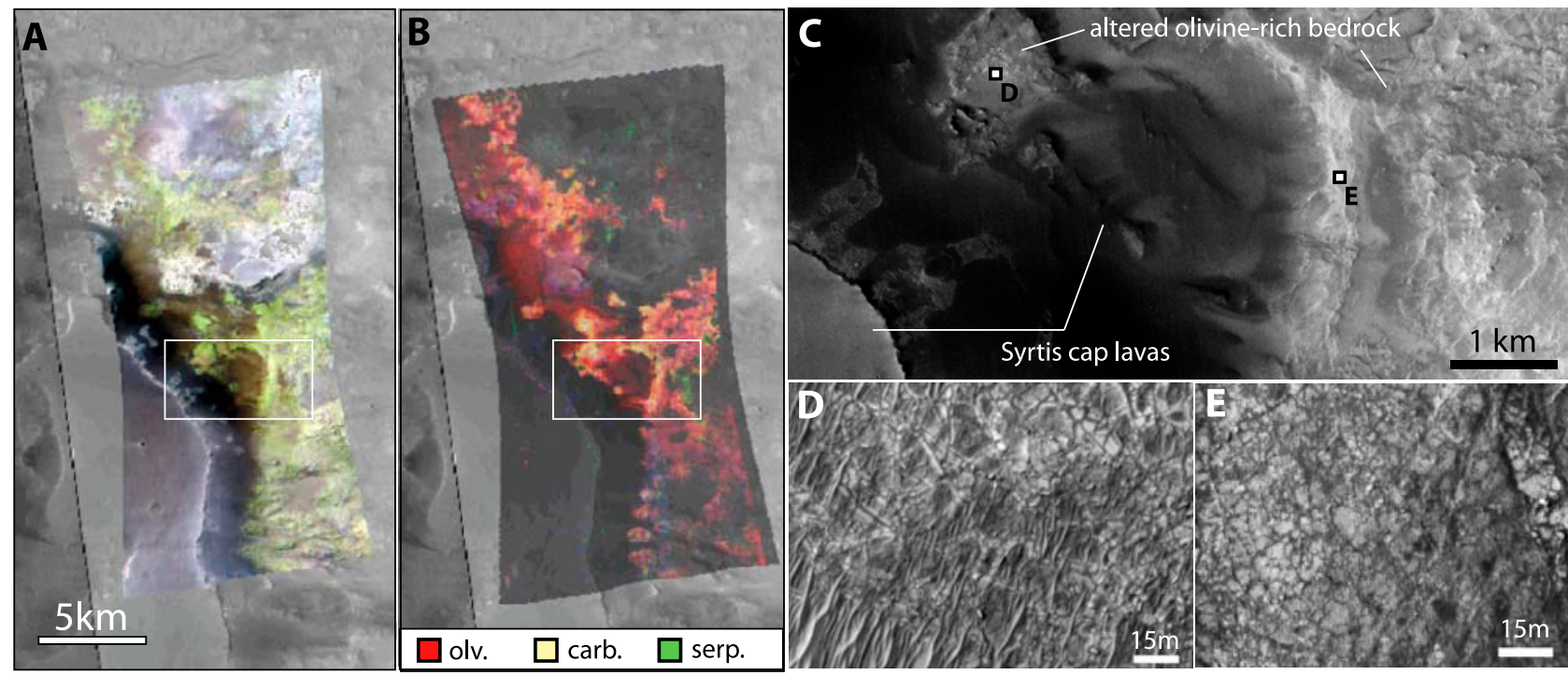

Figure 4. Serpentine in stratigraphic section. (a) False-color (R, 2.38; G, 1.80; B, $1.15 \mu \mathrm{m}$ ) CRISM image HRL0000B072 on a CTX mosaic. The olivine-carbonate-serpentine unit (green) is being exposed from beneath Syrtis lavas (purple). (b) CRISM parameter map (R, OLINDEX; G, D2300; B, BD2500) where olivine appears red, carbonate appears white to pale yellow, and serpentine appears green. (c) The olivine unit and overlying lavas are shown in a subset of CTX image P06_003376_1987_XN. (d, e) Subsets of HiRISE image PSP 9217_1975 showing the meter-scale fracturing characteristic of the altered ultramafic unit.

ation. In over 20 images, distinctive paired absorptions at 2.31 and $2.51 \mu \mathrm{m}$ of comparable width and strength can be uniquely identified as magnesium carbonate [Ehlmann et al., 2008]. However, as noted by Mangold et al. [2007] and Ehlmann et al. [2009], in places the olivine-rich unit instead exhibits characteristic absorptions at 1.91 and $2.32 \mu \mathrm{m}$, due to $\mathrm{H}_{2} \mathrm{O}$ and $\mathrm{Mg}-\mathrm{OH}$ respectively, and the 2.5- $\mu \mathrm{m}$ absorption is weak to absent. This combination of absorptions is not consistent with carbonate but instead implies the presence of an Mg-rich phyllosilicate, either saponite or serpentine.

\section{Discussion}

[12] Contiguous exposures of definitively serpentinebearing materials are small and rare on Mars. This finding represents a combination of the actual distribution of serpentine and the fact that serpentine is difficult to distinguish uniquely from other $\mathrm{Fe} / \mathrm{Mg}$ phyllosilicates, carbonates, and their mixtures. To date, serpentine-bearing materials appear to be restricted to Noachian-aged rocks: mélange terrains near the Claritas Rise and the Nili Fossae, a few impact craters throughout the southern highlands, and an olivinebearing bedrock unit in Nili Fossae. That serpentine exists in these terrains confirms the existence of hydrothermal alteration of ultramafic rocks during the Noachian epoch.

[13] Depending on temperature, $\mathrm{fO}_{2}$, and the activities of $\mathrm{SiO}_{2}, \mathrm{H}_{2} \mathrm{O}, \mathrm{Ca}^{2+}$, serpentinization generates multiple additional products; brucite, talc, and magnetite are most typical [e.g., Frost and Beard, 2007]. Talc and brucite have distinctive IR absorptions but have not been observed, thus implying they are either absent or not optically dominant at IR wavelengths. Magnetite is largely opaque in the nearinfrared and would not be detected by CRISM. Magnesium carbonates are a less common accompanying mineral in serpentinization reactions but can co-occur with serpentine in hydrothermal systems when the $a \mathrm{CO}_{2}$ is moderately high and temperatures are low. This may explain the occurrence of an olivine-carbonate-serpentine unit in the Nili Fossae region. Another possibility is a two-step process: olivine is partially altered to serpentine hydrothermally, and magnesium carbonate subsequently forms during surface weathering. On Earth, magnesite deposits are commonly observed in association with serpentinized ultramafic rocks as a result of surface or near-surface weathering [e.g., Kelemen and Matter, 2008]. Olivine can weather directly to magnesite [Gooding, 1978; Jull et al., 1988]; brucite is also highly susceptible to weathering in the presence of $\mathrm{CO}_{2}$ and is a common precursor mineral for hydrated and magnesium carbonates [Hostetler et al., 1966]. That the Nili-Fossae olivine-carbonate-serpentine unit is heavily fractured on a decimeter to meter scale is consistent with rock fabrics in serpentinites, since the conversion from olivine to serpentine involves a 30-50\% volumetric expansion [Evans, 2004, and references therein].

[14] In Nili Fossae, a clear geologic record of process exists where both the reactants and products of serpentinization are found. The mechanism and timing of serpentine formation is less clear in the crater or mélange settings where rocks lack stratigraphic context. Serpentine may have formed prior to disruption, by cratering or whatever process created the mélange, or may have resulted from hydrothermal activity after the fact. Additional alteration minerals, albeit not directly associated with the serpentinization process, are sometimes found in nearby rocks and include kaolinite, illite and/or muscovite, chlorite, and $\mathrm{Fe} / \mathrm{Mg}$ smectites. This suggests either mixing of pre-existing discrete units, perhaps by impact processes, or variation in precursor lithology or fluid composition and temperature on scales of just a few kilometers as in diatremes where kaolinite, illite, and chlorite form when $\mathrm{pH}$ drops and Eh increases making $\mathrm{Al}$ insoluble [Sader et al., 2007]. 
[15] The global distribution of serpentine shows no correlation with magnetic field anomalies. Serpentine is found in Claritas and western Arabia, which have large magnetic anomalies; near the Nili Fossae, which has no anomaly; and not in Terra Sirenum nor Terra Cimmeria where crustal magnetic sources are most intense. What controls the spatial distribution of the few serpentine occurrences on Mars? It is clearly not as simple as olivine distribution. Serpentine has not been definitively found in Argyre and Terra Tyrrhena, which are regions of elevated olivine abundance [Koeppen and Hamilton, 2008], but multiple craters in apparently olivine-poor Arabia Terra have serpentine. Hydrated silicates are found in craters distributed in nearly all southern highlands terrains, suggesting that water availability was not a limiting factor for serpentine formation. Four plausible hypotheses are that (1) serpentine was once more abundant but has since mostly weathered to other materials, e.g., $\mathrm{Fe} /$ Mg smectite; (2) serpentine distribution follows the distribution of buried, altered ultramafic rocks, which is different from surface composition measurable by orbiting sensors; (3) most olivine-bearing rocks are sufficiently Si-rich that the favored equilibrium hydrothermal alteration assemblage is chlorite- rather than serpentine-rich [Frost and Beard, 2007]; or (4) most alteration conditions were sufficiently oxidizing/low-T that other alteration products, e.g., oxides and smectites, were favored rather than serpentine.

\section{Conclusions}

[16] Presently occurring serpentinization and consequent abiotic or biologically mediated methane production would be occurring in the subsurface and minerals produced could not be observed from orbit. However, it is clear that the serpentinization process operated on Mars in the past. In the Noachian period, formation of serpentine on Mars near Nili Fossae, at the Claritas Rise, and associated with several southern highlands impact craters would have generated $\mathrm{H}_{2}$ and created aqueous habitats appropriate for chemoautotrophic microbial life. Evidence for such processes may be preserved at such sites. While most occurrences of serpentine are in disrupted strata, intact bedrock exposures such as near the Nili Fossae represent targets for future landed exploration.

[17] Acknowledgments. Thanks to D. Cardace, W. Calvin, G. Swayze, S. Wiseman, M. Wolff and two anonymous reviewers for suggestions that improved this manuscript and to the MRO science operations teams for their efforts in collecting a spectacular dataset.

\section{References}

Acuña, M. H., et al. (1999), Global distribution of crustal magnetization discovered by the Mars Global Surveyor MAG/ER experiment, Science, 284, 790-793, doi:10.1126/science.284.5415.790.

Anderson, R. C., et al. (2001), Primary centers and secondary concentrations of tectonic activity through time in the western hemisphere of Mars, J. Geophys. Res., 106, 20,563-20,585, doi:10.1029/2000JE001278.

Bishop, J. L., et al. (2008), Physical alteration of antigorite a Mossbauer spectroscopy, reflectance spectroscopy, and TEM study with applications to Mars, Clay Miner., 43, 55-67, doi:10.1180/claymin.2008.043.1.04.

Calvin, W. M., and T. V. V. King (1997), Spectral characteristics of iron bearing phyllosilicates: Comparison to Orgueil (CI1), Murchison, and Murray (CM2), Meteorit. Planet. Sci., 32, 693-701, doi:10.1111/ j.1945-5100.1997.tb01554.x.
Clark, R. N., G. A. Swayze, R. Wise, K. E. Livo, T. M. Hoefen, R. F. Kokaly, and S. J. Sutley (2007), USGS Digital Spectral Library splib06a, U.S. Geol. Surv. Digital Data Ser., 231.

Ehlmann, B. L., et al. (2008), Orbital identification of carbonate-bearing rocks on Mars, Science, 322, 1828-1832, doi:10.1126/science.1164759.

Ehlmann, B. L., et al. (2009), Identification of hydrated silicate minerals on Mars using MRO-CRISM: Geologic context near Nili Fossae and implications for aqueous alteration, J. Geophys. Res., 114, E00D08, doi:10.1029/2009JE003339.

Evans, B. W. (2004), The serpentine multisystem revisited, in Serpentine and Serpentinites, Int. Book Ser., vol. 8, edited by W. G. Ernst, pp. 5-32, Geol. Soc. of Am., Columbia, Md.

Frost, B. R., and J. S. Beard (2007), On silica activity and serpentinization, J. Petrol, , 48, 1351-1368, doi:10.1093/petrology/egm021.

Gooding, J. L. (1978), Chemical weathering on Mars, Icarus, 33, 483-513, doi:10.1016/0019-1035(78)90186-0.

Hamilton, V. E., and P. R. Christensen (2005), Evidence for extensive, olivine-rich bedrock on Mars, Geology, 33, 433-436, doi:10.1130/ G21258.1.

Hostetler, P. B., R. G. Coleman, F. A. Mumpton, and B. W. Evans (1966), Brucite in alpine serpentinites, Am. Mineral., 51, 75-98.

Jull, A. J. T., et al. (1988), Rapid growth of magnesium-carbonate weathering products in a stony meteorite from Antarctica, Science, 242, 417-419, doi:10.1126/science.242.4877.417.

Kelemen, P. B., and J. Matter (2008), In-situ carbonation of peridotite for $\mathrm{CO}_{2}$ storage, Proc. Natl. Acad. Sci. U. S. A., 105, 17,295-17,300, doi:10.1073/pnas.0805794105.

Koeppen, W. C., and V. E. Hamilton (2008), Global distribution, composition, and abundance of olivine on the surface of Mars from therma infrared data, J. Geophys. Res., 113, E05001, doi:10.1029/2007JE002984.

Lillis, R. J., H. V. Frey, and M. Manga (2008), Rapid decrease in Martian crustal magnetization in the Noachian era: Implications for the dynamo and climate of early Mars, Geophys. Res. Lett., 35, L14203, doi:10.1029/2008GL034338.

Mangold, N., et al. (2007), Mineralogy of the Nili Fossae region with OMEGA/Mars Express data: 2. Aqueous alteration of the crust, J. Geophys. Res., 112, E08S04, doi:10.1029/2006JE002835.

Murchie, S. L., et al. (2009), Compact Reconnaissance Imaging Spectrometer for Mars investigation and data set from the Mars Reconnaissance Orbiter's primary science phase, J. Geophys. Res., 114, E00D07, doi:10.1029/2009JE003344.

Mustard, J. F., et al. (2008), Hydrated silicate minerals on Mars observed by the CRISM instrument on MRO, Nature, 454, 305-309, doi:10.1038/ nature07097.

Mustard, J. F., B. L. Ehlmann, S. L. Murchie, F. Poulet, N. Mangold, J. W. Head, J.-P. Bibring, and L. H. Roach (2009), Composition, morphology, and stratigraphy of Noachian crust around the Isidis basin, J. Geophys. Res., 114, E00D12, doi:10.1029/2009JE003349.

Nazarova, K. A., and C. G. A. Harrison (2000), Serpentinization of Martian crust and mantle and the nature of Martian magnetic anomalies, Eos Trans. $A G U, 81(19)$, Spring Meet. Suppl., Abstract GP31A-06.

Oze, C., and M. Sharma (2005), Have olivine, will gas: Serpentinization and the abiogenic production of methane on Mars, Geophys. Res. Lett., 32, L10203, doi:10.1029/2005GL022691.

Poulet, F., et al. (2005), Phyllosilicates on Mars and implications for early Martian climate, Nature, 438, 623-627, doi:10.1038/nature04274.

Poulet, F., et al. (2007), Martian surface mineralogy from Observatoire pour la Mineralogie, l'Eau, les Glaces et l'Activite on board the Mars Express spacecraft (OMEGA/MEx): Global mineral maps, J. Geophys. Res., 112, E08S02, doi:10.1029/2006JE002840.

Sader, J. A., M. I. Leybourne, M. B. McClenaghan, and S. M. Hamilton (2007), Low-temperature serpentinization processes and kimberlite groundwater signatures in the Kirkland Lake and Lake Timiskiming kimberlite fields Ontario, Canada, Geochem.: Explor., Environ., Anal., 7(1), 3-21, doi:10.1144/1467-7873/06-900.

Schulte, M., D. Blake, T. Hoehler, and T. McCollom (2006), Serpentinization and its implications for life on the early Earth and Mars, Astrobiology, 6, 364-376, doi:10.1089/ast.2006.6.364.

B. L. Ehlmann and J. F. Mustard, Geological Sciences, Brown University, Box 1846, Providence, RI 02912, USA. (bethany_ehlmann@brown.edu)

S. L. Murchie, Johns Hopkins University Applied Physics Laboratory, 11100 Johns Hopkins Rd., Laurel, MD 20723, USA. 